\title{
Análisis del sector portuario español: en la búsqueda de factores que limitan la competencia
}

\author{
María Cabrera Escalante \\ Ancor Suárez Alemán \\ Lourdes Trujillo Castellano \\ Universidad de Las Palmas de Gran Canaria
}

\section{Resumen}

El notable aumento del comercio marítimo mundial a lo largo de las últimas décadas ha potenciado el papel que juegan los puertos españoles en la economía del país. Su situación geoestratégica supone la existencia clara de una serie de ventajas como puerta de entrada al continente europeo, pero también la amenaza de nuevos puertos competidores como los situados en el norte de Africa. El presente artículo realiza un análisis exhaustivo de las diferentes fuentes de competencia (tanto exógenas como endógenas) que encontramos en los puertos españoles, con el objeto de determinar las prácticas restrictivas a la competencia en la actualidad además de las potenciales limitaciones a la misma, y sus posibles efectos. Aspectos tales como el correcto diseño de los contratos de concesión para la introducción de participación privada y los sistemas de regulación que atiendan a las características competitivas de cada puerto aparecen como fundamentales en un futuro esquema portuario.

Palabras claves: competencia portuaria, sistema portuario español, fuentes de competencia.

Clasificación JEL: L10, L91, R41, R42, R48.

\begin{abstract}
The remarkable growth of world maritime shipping over the last decades has enhanced the role of Spanish ports in the economy of the country. Although we may acknowledge the geography as an advantage for the country in terms of proximity to main trade corridors, the competition from new competing ports-especially those located in the North of Africa-generates the need of improving port services and competitiveness to effectively compete. This paper addresses the different sources and levels of competition (both exogenous and endogenous) in the Spanish port system. The objective is to identify actual and potential anti-competitive behaviours and factors throughout the system. The proper design of concession contracts to introduce private participation together with a regulation that consider the specific port competitive conditions turn into vital for the future of Spanish ports.
\end{abstract}

Keywords: port competition, Spanish port system, sources of competition.

JEL classification: L10, L91, R41, R42, R48. 


\section{Introducción}

En la actualidad alrededor del 80 por 100 del comercio mundial se lleva a cabo por mar (COM, 2009). Esto significa que alrededor de un 80 por 100 de la mercancía precisa de un barco para ser transportada desde el origen, donde es producida, hasta el destino final donde será consumida. Este dato supone igualmente que alrededor del 80 por 100 de los bienes que vemos, si apartamos la vista de esta lectura, han pasado por algún puerto.

$\mathrm{Si}$ atendemos exclusivamente al continente europeo, esta cifra aumenta hasta el 90 por 100 del comercio exterior, cantidad que se sitúa en el 40 por 100 para el comercio intrarregional mediante las actuales rutas de transporte marítimo de corta distancia (TMCD, Short Sea Shipping, SSS, en inglés). El hecho de que estas últimas tengan una cuota de mercado inferior responde a un hecho muy claro: el efecto de la competencia. Mientras que en largas distancias no existen modos de transporte alternativos que puedan constituirse como sustitutivos viables -salvo para el caso de mercancías de alto valor y poco volumen, para las que el transporte aéreo tiene ventajas por su mayor velocidad-, en cortas distancias la carretera o el tren suponen alternativas viables al tráfico marítimo. Por tanto, en un análisis de competencia inicial podríamos fácilmente acordar que existe un mayor riesgo de restricción a la misma en tráficos de larga distancia, y por tanto en puertos especializados en las mismas.

A este hecho debemos sumar que la UE prevé que el comercio marítimo aumente desde los 3,8 billones de toneladas contabilizados en 2006 hasta los 5,3 billones estimados para 2018 (COM, 2009a). La principal consecuencia de esto resulta en la necesidad de desarrollar una infraestructura -en este caso, el puerto y su hinterland $-^{1}$ capaz de hacerse cargo de un incremento del tráfico de entre un 30 por 100 y un 50 por 100 para el periodo 2030-2050 (COM, 2012a).

Sin embargo, el notable aumento del tráfico de mercancías $-\mathrm{y}$ en concreto el relativo al tráfico de contenedores- no es un hito exclusivo del continente europeo. La profunda integración de las cadenas de suministro, el conocido como tráfico de transbordo ${ }^{2}$, el notable aumento del comercio de bienes de primera necesidad así como los mayores volúmenes de demanda de productos importados han provocado que, de acuerdo a los datos provistos por el Banco Mundial, el mundo en desarrollo mueva en la actualidad el 54 por 100 del tráfico de contenedores de todo el mundo.

Para España, este hecho posee especial relevancia. La actividad del sistema portuario estatal aporta cerca del 20 por 100 del PIB del sector del transporte, lo que representa el 1,1 por 100 del PIB español. Asimismo, genera un empleo directo

1 El término hinterland hace referencia a la región de influencia que abarca un puerto, y que no se guía únicamente por criterios geográficos, sino por otros tales como mercados o población a los que abastece. Por su parte, un puerto se define como la infraestructura esencial que actúa como nodo del transporte marítimo y puerta de entrada/salida del comercio marítimo hacia/desde una determinada región.

2 El tráfico de transbordo es aquel que pasa por un determinado puerto pero que no tiene como destino final el mismo y por tanto no requiere de un uso completo de la infraestructura portuaria (como carga y descarga, por ejemplo). 
de más de 35.000 puestos de trabajo y de unos 110.000 de forma indirecta. Cabe señalar que la importancia de los puertos como eslabones de las cadenas logísticas y de transporte viene avalada por las siguientes cifras: por ellos pasan el cerca del 60 por 100 de las exportaciones y el 85 por 100 de las importaciones, lo que representa el 53 por 100 del comercio exterior español con la Unión Europea y el 96 por 100 con terceros países, según datos de Puertos del Estado (2012). En cuanto a la presión competitiva, si bien la situación geoestratégica de España supone la existencia clara de una serie de ventajas como puerta de entrada al continente europeo -se sitúa en el centro de las rutas entre Asia y Norteamérica- ${ }^{3}$ también le obliga a enfrentarse la amenaza de nuevos puertos competidores como los situados en el norte de África. Por poner un ejemplo, Maersk Line, la naviera líder en el tráfico marítimo mundial, amenazaba en 2010 con trasladar del principal puerto de contenedores español, Algeciras, a Tanger-Med (Marruecos) alrededor de medio millón de contenedores anuales debido a las condiciones más ventajosas.

De lo anterior se deriva la importancia de garantizar el buen funcionamiento de los servicios portuarios en España y la competitividad de los mismos. El objetivo básico de un puerto es proporcionar un traslado rápido y seguro de mercancías y pasajeros a través de sus instalaciones, de forma que se minimicen los tiempos de espera y se proporcionen los servicios necesarios al mínimo coste posible y, por tanto, con un elevado nivel de eficiencia.

Sin embargo, en muchas ocasiones los puertos son percibidos como cuellos de botella que reducen la competitividad del transporte marítimo de las regiones (Wilmsmeier et al., 2006). De acuerdo al indicador logístico del Banco Mundial para 2012 (Logistics Performance Indicator, LPI, 2014), que reúne la valoración por parte de transportistas del sistema logístico y su infraestructura asociada, España se sitúa por detrás de países como Alemania, Francia, Holanda o Reino Unido.

La evidencia empírica muestra cmo la modernización del sector portuario llevada a cabo en muchos países ha contribuido a la mejora en el funcionamiento de estas infraestructuras. Sin embargo, la naturaleza de los puertos ha favorecido tradicionalmente a la existencia de limitaciones a la libre competencia en las mismas: la disposición de tráficos cautivos, la escasa competencia entre terminales, la regulación de las tasas portuarias, el excesivo poder concentrado en ciertos agentes, etcétera.

Por todo ello, este artículo realiza un análisis exhaustivo de las diferentes fuentes de competencia tanto exógenas como endógenas que encontramos en los puertos españoles. La intención es determinar las prácticas restrictivas a la competencia en la actualidad además de las potenciales limitaciones a la misma, y sus posibles efectos. En definitiva, pretendemos conocer qué parte de estos cuellos de botella son debidos a problemas de competencia, y cómo abordarlos.

3 Recientemente, el presidente de Puertos del Estado declaraba que aunque seguirá la línea Europa-Asia por el Canal de Suez, la ampliación del Canal de Panamá para buques de mayor calado impulsará el transporte marítimo desde Asia al Pacífico por este paso, y los puertos españoles -ha dicho- «van a ser capaces de aprovechar las nuevas líneas entre ambos lados». Fuente: http://www.europapress.es/economia/noticiaeconomia-puertos-estado-cree-ampliacion-canal-panama-beneficiara-espana-20131011173748.html 
Tras presentar brevemente el sistema portuario español, analizamos de manera detallada los diferentes niveles de competencia dentro del mismo y determinamos los factores de principales de riesgo. Con todo ello, planteamos una matriz de análisis de competencia integral atendiendo a las diferentes fuentes y niveles de la misma, para finalmente ofrecer una serie de recomendaciones y propuestas de futuros análisis.

\section{El sistema portuario español}

El sistema portuario español está integrado por 46 puertos de interés general y 28 autoridades portuarias. Todos ellos son coordinados por Puertos del Estado, organismo público dependiente del Ministerio de Fomento y encargado de la política portuaria $^{4}$. Esta industria no es ajena a los cambios acontecidos en al panorama mundial. Las diversas actualizaciones de las leyes portuarias españolas -la última en el 2011- han adaptado la industria portuaria a las tendencias internacionales. Así, aparece en España una estructura portuaria organizativa tipo landlord, que implica que los servicios son prestados por empresas privadas y la autoridad portuaria se limita a gestionar e invertir en infraestructura, además de llevar a cabo labores de regulación técnica y económica, teniendo también facultades para la planificación portuaria (Cabrera et al., 2014). Bajo este sistema la participación privada no sólo tiene cabida sino que se persigue como medida para promocionar el transporte marítimo.

Con la integración de la economía en general y el sector portuario en especial dentro de la competitiva red internacional se inició un proceso legislativo que buscaba incentivar los niveles de competitividad de los puertos públicos tanto dentro de la propia red nacional como de cara a la competencia internacional, la inclusión de la iniciativa privada y el sistema de concesiones como práctica común así como una importante reducción de costes portuarios ${ }^{5}$. En este sentido fueron claves los dictámenes recogidos en la Ley 27/1992 de Puertos del Estado y de la Marina mercante y su posterior modificación con la Ley 62/1997 que daban forma a la nueva organización de los puertos y sus órganos administrativos; y la posterior Ley 48/2003, de régimen económico y de prestación de servicios en los puertos de

${ }^{4}$ La Constitución Española recoge en su articulo 149 referente a las 'Competencias Exclusivas del Estado', la titularidad de puertos y aeropuertos de interés general. En la actualidad, las funciones de Puertos del Estado son 1) ejecución de la política portuaria del gobierno y la coordinación y el control de eficiencia del sistema portuario de titularidad estatal, en los términos previstos en esta Ley; 2) la coordinación general con los diferentes órganos de la Administración General del Estado que establecen controles en los espacios portuario y con los modos de transporte en el ámbito de competencia estatal, desde el punto de vista de la actividad portuaria; 3 ) la formación, la promoción de la investigación y el desarrollo tecnológico en materias vinculadas con la economía, gestión, logística e ingeniería portuarias y otras relacionadas con la actividad que se realiza en los puertos; y 4) la planificación, coordinación y control del sistema de señalización marítima español, y el fomento de la formación, la investigación y el desarrollo tecnológico en estas materias. La coordinación en materia de señalización marítima se llevará a cabo a través de la Comisión de Faros, cuya estructura y funcionamiento se determinará por el Ministerio de Fomento. Fuente: www.puertos.es.

${ }^{5}$ Ley 48/2003, de régimen económico y de prestación de servicios de los puertos de interés general. 
interés general, en donde quedaba reflejada la voluntad estatal de incrementar la competencia y competitividad a lo largo del sistema portuario español así como la inclusión de la iniciativa privada como elemento clave en el desarrollo del sector. El marco legislativo que se ha ido conformando desde entonces queda hoy definido a través de la siguiente jurisprudencia:

- El Texto refundido de la Ley Puertos del Estado y de la Marina mercante de 2011, que recoge y resume la legislación anterior.

- El Texto refundido de 2011 de la Ley de contratos del sector público, de contratos del sector público.

En la búsqueda de un mayor grado de competitividad han surgido algunos problemas dentro de la red portuaria española con respecto a las inversiones y a la competencia entre puertos, restándole competitividad al sistema en su conjunto y a algunos puertos en particular. Así pues, fruto de la delegación de competencias a las distintas regiones y autoridades portuarias, el sistema portuario vivió un aluvión de proyectos de inversión multimillonarios que no siempre atendieron a un objetivo puro de rentabilidad ${ }^{6,7}$. Como recoge la CEPAL (2012) para el caso español, existe una práctica común en el uso de inversión en infraestructura como estrategia válida en la competitividad de los puertos. El informe señala que tan solo los puertos con un mayor tráfico dentro de la red española pueden, hasta cierto punto, ligar sus tráficos con su volumen de inversión.

En el contexto internacional, la especialización de los puertos se ha empleado como estrategia de crecimiento. Las tendencias globales, con el espectacular auge del tráfico de contenedores y la necesidad de acomodar buques cada vez más grandes, han determinado la necesidad de contemplar nuevas inversiones para competir en un marco cada vez más competitivo. Aun así, la escasa inversión en especialización hasta la fecha en distintos puertos del sistema español no ha demostrado tener efectos positivos sobre el tráfico (CEPAL, 2012).

Por el lado de los costes, el sistema portuario español presenta una serie de particularidades que afectan de manera directa a la competitividad de los puertos. En este sentido, la mano de obra presenta un desafío especial por su influencia sobre la competitividad de los mismos (Núñez Sánchez et al., 2012). En el caso de España, los estibadores -trabajadores que se encargan de las labores de carga y descarga y que están constituidos en organizaciones con un fuerte poder sindical- gozan de un

${ }^{6}$ Ley 27/1992 de Puertos del Estado y de la Marina mercante y su posterior modificación con la Ley 62/1997 y Ley 48/2003, de régimen económico y de prestación de servicios en los puertos de interés general donde se recogían la nueva organización del sistema portuario español y sus competencias por un lado y la voluntad de aumentar la competitividad del sector y la inclusión de la participación privada en su actividad.

7 GARCÍA ALONSO y MARTÍN BOFARULL (2007) mostraban, como resultado del estudio en los puertos de Bilbao y Valencia en el periodo 1992-2002, que la relación entre gasto en infraestructura y ganancia de eficiencia no era necesariamente directa ni proporcional y, por tanto, no podía entenderse la inversión en inmovilizado como eje único de la mejora de competitividad y factor de atracción de tráfico hacia los puertos españoles. 
fuerte dominio en el sistema portuario español. Los tribunales europeos, que ya en varias ocasiones han reclamado su revisión, pueden cercenar en breve sus privilegios derivados de una fuerza laboral que tradicionalmente ha estado presente en todos los puertos españoles ${ }^{8}$, recordando las bases del Tratado de la Unión Europea cuyas disposiciones en materia de libertad de establecimiento se aplican plenamente a las actividades realizadas por las entidades responsables de la contratación de trabajadores portuarios. Pese al acuerdo alcanzado en febrero de 2014 para el mantenimiento del statu quo de la estiba en España hasta $2018^{9}$, el fallo del Tribunal de Justicia de la Unión Europea esperado a finales de 2014 se prevé condenatorio contra España ${ }^{10}$. Estas prácticas restrictivas de la competencia que impiden la libre contratación por parte de los operadores ha sido objeto de sentencia también por parte de la Comisión Nacional de la Competencia española que así lo refleja en su expediente $2805 / 07^{11}$. Del mismo modo, las condiciones de estiba -que imponen la tenencia de titulaciones impartidas por las propias corporaciones- suponen sueldos con bases superiores a 50.000 euros brutos anuales, además de poseer un exceso de capacidad de gestión sobre toda la actividad, comprometiendo los calendarios de navieras ${ }^{12,13}$.

\footnotetext{
${ }^{8}$ En octubre de 2012 la Comisión Europea daba dos meses de plazo al Gobierno español para liberalizar los servicios de estiba y revisar los privilegios laborales del colectivo (12/10/2012, http://www.02b.com/es/ notices/2012/10/la_ue_lanza_un_ultimatum_para_acabar_con_los_privilegios_de_los_7.000_trabajadores_ de_estiba_4216.php).

${ }^{9}$ En febrero de 2014 La Coordinadora estatal de Trabajadores del Mar llegaba a un acuerdo con el Ministerio de Trabajo para mantener el statu quo de la estiba hasta 2018 (05/02/2014, http://www.lne.es/ aviles/2014/02/05/da-finalmente-bueno-acuerdo-negociado/1538398.html).

${ }^{10}$ España y Bélgica se verán afectados por la decisión del Tribunal de Justicia de Luxemburgo que se muestra firme en su ataque a los modelos de estiba no acordes a los tratados fundacionales de la Unión Europea. (07/10/2014), http://www.europapress.es/economia/transportes-00343/noticia-economia-fallo-tjueestibadores-espanoles-inminente-probablemente-condenatorio-puertos-20141007142154.html.

${ }^{11}$ El expediente resultaba en multa superior a $900.000 €$ a la Asociación Nacional de Empresas Estibadoras y Consignatarias de Buques (ANESCO), $168.000 €$ a Coordinadora Estatal de Trabajadores del Mar (CETM); $4.000 €$ a la Confederación Intersindical Galega (CIG) y $3.000 €$ a Laginle Abertzaleen Batzordeak (LAB) por acuerdo anticompetitivo para impedir o dificultar el acceso al mercado de los servicios portuarios.

12 En 2012 la media salarial era de $89.000 €$ netos al año y privilegiadas condiciones laborales en cuanto a jornadas de trabajo y edad de jubilación. (12/02/2014), http://www.02b.com/es/notices/2012/10/la_ue_lanza_.

13 Ejemplos recientes de la influencia de los estibadores en la actividad portuaria son la paralización en abril de 2013 del Puerto de Vigo como consecuencia de la protesta de la Sociedad Anónima de Gestión de Estibadores Portuarios por la distribución de las cargas laborales (18/04/2013, http://www.farodevigo.es/ gran-vigo/2013/04/18/plante-estibadores-paraliza-puerto-retiene-24-horas-cuatro-grandes-buques/793281. html) o la huelga de los estibadores del Puerto de Castellón ante las medidas de liberalización adoptadas en la reforma legislativa de 2011 (02/05/2003, http://www.elperiodicomediterraneo.com/noticias/castellon/ estibadores-dicen-solo-pueden-protestar-huelga_49382.html).
} 


\section{Competencia en puertos}

Si bien algunos estudios previos han abordado la importancia de la competencia en puertos (Verhoeff, 1981; Slack 1985), no es hasta mediados de los 90 cuando la literatura portuaria se expande, principalmente motivado por el auge de la contenedorización. Así, en las dos últimas décadas numerosos estudios han abordado el análisis de competencia en estas infraestructuras, principalmente en términos intraportuarios (Goss, 1999; Chlomoudis y Pallis 1998; Fleming y Baird 1999). Del mismo modo, diversos análisis sectoriales han centrado su foco en las implicaciones sobre la competencia de la modernización de la industria portuaria (De Langen, 2002; Haralambides, 2002; Notteboom, 2002; Song, 2003; Defilippi, 2004; De Langen, 2006).

Por su parte,el sector portuario español ha recibido igualmente una creciente atención en las últimas décadas, especialmente en términos de competitividad. Destacan De Rus et al. (1995), Trujillo y Nombela (1999) y Castillo Manzano y López (2003), quienes analizan las ventajas competitivas de la privatización y los esquemas regulatorios aplicables. Más recientemente, González Laxe (2012) analiza la problemática relativa al impacto de la crisis económica en la competitividad del sistema portuario español.

Tradicionalmente, la literatura económica ha reconocido tres formas principales de introducir competencia en el sector del transporte (Meyer, 1959; Verhoeff, 1981; De Langen y Pallis, 2006; entre otros): Competencia por el mercado, competencia en el mercado y competencia entre mercados. La primera competencia por el servicio portuario, se relaciona con la concurrencia a los procesos de gestión del algún servicio que por sus características no permite la competencia en el mercado. En segundo lugar, la competencia en el puerto se centra en la liberalización de los servicios portuarios y la introducción de competencia en los mismos (libertad de entrada y salida de operadores). Por último la competencia entre puertos o servicios portuarios hace relación con la competencia con puertos cercanos con características similares y en los que el hinterland portuario se solapa.

\section{ESQUEMA 1}

FUENTES DE COMPETENCIA ANALIZADAS

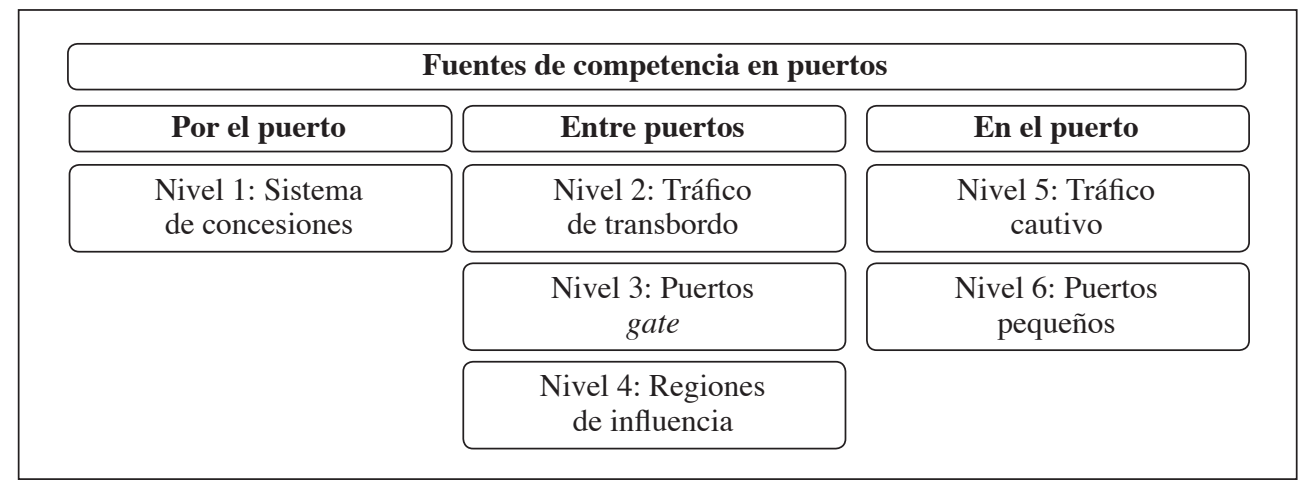

FUENTE: Elaboración propia. 
El Esquema 1 sintetiza las fuentes de competencia analizadas a continuación para el sistema portuario español, junto con los niveles asociados a las mismas.

\subsection{Competencia por el puerto}

- Primer nivel de competencia: sistema de concesiones. Cuando la naturaleza del tráfico de un puerto o la supervivencia de una terminal no se ven sujetas a las presiones que un mercado competitivo imprime, han de ser mecanismos alternativos los que empujen al mantenimiento de un adecuado grado de eficiencia. En este sentido, las esquemas de concesión han demostrado ser una herramienta no sólo útil a la hora de desarrollar grandes proyectos en infraestructura de transporte sino también en la búsqueda de soluciones pre-competitivas para su operación (Roumboutsous et al., 2013) ${ }^{14}$.

Sin obviar el claro papel como respuesta a la necesidad de financiación en proyectos de gran envergadura como puertos o terminales -además del aprovechamiento del know-how que introducen las empresas privadas en la gestión de los mismos (González y Trujillo, 2009) - resulta imprescindible contemplar el efecto sobre la competencia de dicho proceso. Desde el punto de vista de la competencia, los procesos de concesión de infraestructura son percibidos como una vía para introducir competencia en un activo que podría disfrutar libremente de un monopolio de facto. De este modo, al incorporar procesos de concurrencia competitiva para la gestión en monopolio de un determinado puerto o terminal se introducen incentivos a actuar de manera competitiva tanto a través de las condiciones para la concurrencia como para el mantenimiento de la concesión.

De este modo, los concursos públicos para otorgar la concesión de operación de un puerto o terminal deberían fomentar la competencia entre los diferentes operadores en una etapa inicial al funcionamiento de la misma. Sin embargo, estos esquemas de financiación y operación de infraestructuras pueden ser realizados bajo marcos y/o condiciones que no garantizan un desempeño correcto de los mismos. De este modo, los procesos de concesión por un determinado puerto o terminal pueden también dar lugar a importantes fracasos que se traducen en grandes pérdidas para el sector

${ }^{14}$ Como señala GUASCH (2004) en la provisión de los servicios de infraestructuras, la exclusiva participación del sector público puede conducir a una situación de prestación limitada y un escaso nivel de eficiencia y calidad junto con el peso de importantes necesidades de inversión. Así pues, la introducción de la participación privada en estos servicios comúnmente generan una mejora en términos de eficiencia así como un aumento los estándares de calidad (GUASCH et al., 2013; ANDRÉS et al., 2007; GONZÁLEZ y TRUJILLO, 2009). Las colaboraciones público-privadas (PPPs, por sus siglas en inglés) en sus diferentes esquemas han demostrado ser un vehículo especialmente adecuado para el desarrollo de grandes infraestructuras de transporte tal y como demuestra la experiencia internacional (ver nota 13). Sólo en la última década la inversión en PPPs a nivel mundial en infraestructura de transporte ha superado los 367.259 millones de dólares (ver nota 13) - de los que 62.805 millones corresponden a proyectos en puertos- y dentro del continente europeo los proyectos de transporte representan el 59 por 100 del valor total de mercado en las colaboraciones público-privadas (EPEC, 2013). 
público. En este sentido el correcto diseño de los contratos de concesiones así como las condiciones de los concursos de los mismos se tornan cruciales para el éxito de las colaboraciones público-privadas en términos de defensa de la competencia. La correcta asignación y especificación de riesgos en la redacción de los contratos es uno de los aspectos más críticos para el buen funcionamiento de las colaboraciones público-privadas (Theys et al., 2010) ${ }^{15}$

El modelo de concesiones español ha sido objeto de especial atención en los últimos años no sólo por parte de reguladores e investigadores, sino también de la prensa, haciéndose eco de diferentes casos donde una deficiente especificación y asignación de los riesgos de un proyecto se traducen en importantes sobrecostes. La reciente oleada de noticias denunciando la falta de adecuación de los presupuestos públicos a las necesidades del país, la poca rigurosidad de algunos proyectos así como los procesos de concesión dudosamente competitivos junto a las cuantiosas pérdidas que han caído en el saco roto de la hacienda pública han puesto en el punto de mira el sistema de concesiones al completo. Debido a su intensidad de inversión, las infraestructuras de transporte han sido especialmente consideradas. En el periodo comprendido entre 2008 y 2014 el Gobierno ha corrido con sobrecostes por un valor aproximado de 10 billones de euros en la construcción de proyectos de carretera, ferrocarril y puertos. De ellos, 5,2 billones se corresponden con la modificación de proyectos ya terminados, 4,1 billones fueron destinados a cubrir puros sobrecostes y 900 millones de euros a expropiaciones de terreno ${ }^{16}$. En algunos casos, ante el riesgo de quiebra de los operadores de las infraestructuras, éstas han sido resueltas por el Estado, quien ha asumido la responsabilidad de parte de sus deudas. Ante esta situación, la Unión Europea ha hecho un llamamiento al gobierno español para que instaure definitivamente un sistema de inversión más riguroso para los proyectos de infraestructura de transporte ${ }^{17}$.

Con respecto a las diferentes naturales de riesgo que forman parte de los esquemas de concesión en proyectos de transporte, la actual legislación española en la materia establece que la mayor parte del riesgo ha de ser asumida por el socio privado. Sin embargo, como apuntan Vasallo y Gallego (2005), la renegociación económica de los contratos de este tipo en España está permitida bajo tres circunstancias: cuando el sector público, en beneficio del interés general impone alteraciones sobre los términos de contrato iniciales; cuando la administración pública contratante lleva a cabo acciones imprevistas no contempladas en el contrato y que afecten a los resultados del proyecto, $\mathrm{y}$; en casos de fuerza mayor.

15 En cuanto a las condiciones de los concursos y en el caso particular de puertos no puede hablarse de un proceso único o modelo específico de concesión que garantice el éxito de los mismos (FARREL, 2012). SIEMONSMA et al. (2012) apuntan que los contratos de PPP en puertos contribuyen más profundamente al sector económico cuando son debidamente específicos y presentan una completa identificación de la asignación de la inversión, las responsabilidades operacionales y financieras y el reparto de riesgos entre las partes. Asimismo señala las ventajas de un proceso de diálogo en el proceso de concesión.

${ }^{16}$ El País, 13/05/2014. http://elpais.com/elpais/2014/05/13/inenglish/1399990193_399229.html?rel=rosEP.

${ }^{17}$ COM (2014) y SWD (2014). 
De la experiencia española en la materia destacan como principales elementos distorsionadores del éxito en los contratos de concesión los siguientes:

- Riesgo de la construcción: sobrecostes de las infraestructuras. Las infraestructuras portuarias no son ajenas a la existencia de sobrecostes en los procesos de diseño y construcción. Es importante tener en cuenta que dentro de las concesiones en el sector portuario español no existe una fase previa de negociación (Vasallo y Gallego, 2005). Es la administración contratante quien publicita un determinado contrato que es aceptado, junto con las condiciones del concurso, por las distintas empresas que deciden formar parte del mismo. Teniendo en cuenta esta particularidad no es inusual asistir a un proceso de renegociación del contrato a lo largo de la vida de la concesión que puede concluir en la alteración de los costes o de las tarifas aplicables por el operador sobre las inicialmente aceptadas. Este problema propio de la idiosincrasia de los concursos en infraestructura portuaria supone en definitiva una falta de especificación de la asignación de riesgos del proyecto en la redacción de los contratos. Ejemplo de ello son el puerto de Gijón -en donde los sobrecostes han sido considerados excesivos por parte de la Unión Europea, que exige la devolución de más de 250 millones de euros por fraude en la ejecución del proyecto- ${ }^{18} \mathrm{o}$ el nuevo complejo portuario de A Coruña, que ha sufrido varios ajustes de presupuesto, donde se ha pasado de los 370 millones de euros con los que la oferta fue adjudicada, a un coste final estimado en más de 700 millones $^{19}$. En el caso del puerto de Cádiz, los sobrecostes imputables a las obras han venido del lado de un alto número de pecios encontrados durante las obras, cuya recuperación en base a su valor patrimonial ha llevado a un desembolso de unos 2,5 millones de euros ${ }^{20}$.

- Riesgo financiero. Es el caso de las complicaciones financieras en la ampliación del puerto de Cádiz, donde aún se desconoce si la Unión Europea destinará finalmente los 120 millones de euros que esperaba recibir el proyecto de Bruselas, podrían acabar por paralizar las obras con más de dos tercios de la infraestructura construida. A esperas de una respuesta por parte de las autoridades europeas que se ha dilatado especialmente, la Autoridad Portuaria de la Bahía de Cádiz recurrió a la deuda externa. A día de hoy los sobrecostes ascienden a medio millón de euros por el pago de intereses de la deuda contraída para financiar las obras ${ }^{21}$.

- Riesgo sobre ingresos: errores de predicción de demanda. El Tribunal de Cuentas Europeo ha afirmado que varios millones de euros de financiación europea en proyectos del sector portuario se han desperdiciado o ha ido a parar a infraestructuras completamente ineficientes o sin uso (TCE, 2012). De este informe se desprende

\footnotetext{
18 (12/04/2014). http://politica.elpais.com/politica/2014/04/12/actualidad/1397327343_281884.html.

19 (26/03/2014). http://elpais.com/elpais/2014/03/26/inenglish/1395835284_329391.html.

${ }^{20}$ (20/03/2014). http://ccaa.elpais.com/ccaa/2014/03/20/andalucia/1395342869_426491.html.

${ }^{21}$ (27/05/2014). http://ccaa.elpais.com/ccaa/2014/05/27/andalucia/1401205118_012929.html.
} 
que un 59,25 por 100 de los proyectos de transporte auditados han fracasado en el cumplimiento de los objetivos propuestos (Suárez-Alemán y Hernández, 2014). Entre ellos, destaca el puerto de Arinaga en Gran Canaria, con una inversión que alcanzó los 23.5 millones de euros dando como resultado un puerto sin tráfico alguno ${ }^{22}$.

- Riesgo regulatorio: Nos encontramos por ejemplo el caso de las distintas concesiones otorgadas al grupo Grimaldi en el puerto de Barcelona, las cuales has despertado el interés por posibles procesos de concentración a través de este tipo de contratos (Cabrera et al., 2014). En julio de 2013 comenzó la operación de la nueva terminal de ferrys en el Puerto de Barcelona a cargo del grupo Grimaldi ${ }^{23}$. El objetivo de esta terminal pasa por profundizar en el tráfico de corta distancia desde Barcelona y en dirección a los distintos nodos de la costa mediterránea. Precisamente son este tipo de rutas las que opera la naviera Grimaldi quien gestiona a su vez la operación en otras terminales para este tipo de tráfico dentro del corredor, así como como las terminales del puerto de Civitavecchia y el de Valencia. Así pues, este holding atesora un importante poder de mercado dentro del corredor mediterráneo entre España e Italia para el transporte de corta distancia ${ }^{24}$. Lo reseñable de este caso -del que no se han publicado los detalles explícitos del concurso o el contrato- es que, si bien no tiene por qué ser una práctica dañina per se con la apropiada regulación, la concentración de poder de mercado debería ser tenida en cuenta en los procesos de concesión y las distintas administraciones deberías plantearse consideraciones más allá del impacto intra-puerto de una concesión ${ }^{25}$.

Así pues, como elementos clave para garantizar el mejor funcionamiento en la utilización de los esquemas introducción de competencia por el puerto, podemos destacar los siguientes: 1) contratos explícitos y exhaustivos con un reparto claro y detallados de riesgos; 2) los procesos de diálogo entre las partes para la elaboración de los contratos como mejora alternativa a la renegociación; 3) predicciones de demanda realistas; y 4) análisis exhaustivo de las implicaciones de las concesiones sobre los procesos de concentración del tráfico en un número reducido de agentes.

22 (26/04/2012), http://www.abc.es/20120426/comunidad-canarias/abcp-censura-desembolso-para-puerto-20120426.html.

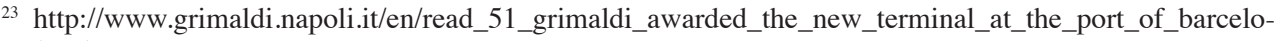
na.html.

24 Ver www.shortsea.es.

${ }^{25}$ El poder del grupo Grimaldi en el corredor mediterráneo ha sido puesto de manifiesto incluso por sus competidores en el sector. Así el Consejero Delegado de Acciona-Transmediterránea declaraba que el holding había impedido la consolidación de la naviera Balearia en las rutas a Civitavecchia. Consultar la noticia en http://www.puertosynavieras.es/noticias.php/Grimaldi-y-Balearia-rompen-UTE-y-presentan-sendas-ofertasa-Moll-Costa/11019 (23/06/2011). 


\subsection{Competencia en puertos}

- Segundo nivel de competencia: tráfico de transbordo. Aunque la labor de un puerto como nodo del transporte marítimo y facilitador del comercio es común a todos, bien es cierto que podemos considerar ciertas especificidades que determinan un entorno más o menos competitivo. Es el caso de aquellos grandes puertos dotados con determinadas instalaciones (terminales) para atender el conocido como tráfico de transbordo. Este hace referencia al tráfico practicado por grandes navieras que operan líneas regulares de larga distancia (deep-sea traffic). Entre este tipo de puertos encontramos fuertes niveles de competencia, forzando a los puertos $-\mathrm{y}$ en particular a sus terminales- a aumentar sus niveles de competitividad a la hora de ofrecer combinaciones óptimas de tiempo/precio para las empresas que demandan sus servicios. En estos, la amenaza de puertos competidores no solo se reduce a los considerados como «puertos vecinos», sino a otros grandes hubs que puedan llevar a las grandes navieras a realizar ligeros cambios en sus rutas para disfrutar de mejores condiciones $^{26}$. Por tanto, los puertos especializados al tráfico de transbordo podrían resultar ser desplazados más fácilmente del mercado por otros puertos rivales. Por poner un ejemplo, en 2010 la multinacional y líder en el tráfico marítimo Maersk Line amenazaba con trasladar del principal puerto de contenedores español, Algeciras, a Tanger-Med (Marruecos) alrededor de medio millón de contenedores anuales debido a las condiciones más ventajosas. En concreto, la compañía aludía a un reducción del 20 por 100 en el coste final de un contenedor si optaban por el puerto africano. Esto suponía una pérdida de alrededor de 35 millones de euros al año para el puerto español. Por tanto, el puerto de Algeciras podría empezar a perder su supremacía en el tráfico de contenedores en el Mediterráneo ${ }^{27}$. Las crecientes conexiones del norte de África con Yibuti, Gabón, Panamá o Brasil suponen igualmente una amenaza a puertos importantes dentro del sistema portuario español como es el de Las Palmas en Gran Canaria. Durante el primer tercio del 2014, el principal puerto marroquí ya movía tres veces más que el canario, con unas perspectivas de crecimiento del 30 por 100. Igualmente, Cagliari, Gioia Tauro y Marsaxlokk compiten por ser puerto de trasbordo en el Mediterráneo central (Rúa-Costa, 2006). Del mismo modo, el puerto de Sines (Portugal) ha experimentado en los últimos años el mayor crecimiento en la península ibérica, siendo de gran amenaza a los puertos españoles. En este respecto, el incremento de la competitividad en costes y tiempos, junto con una adecuada regulación, se convierten en una pieza clave del juego.

${ }^{26}$ En este sentido, FAGEDA y GONZÁLEZ-AREGALL (2014) determinan la existencia de una fuerte relación entre las tasas portuarias y la cantidad de tráfico generada por los puertos españoles. Del mismo modo, los autores muestran cómo los ingresos por tonelada son mayores en aquellos puertos donde operan más líneas regulares internacionales y donde los operadores de terminales son internacionales, mientras que son menores por el efecto de la competencia.

${ }^{27}$ A partir del análisis de los factores que afectan a la competitividad portuaria a partir de encuestas a los agentes que operan en el puerto de Algeciras, ACOSTA et. al. (2007) determinan cómo el tráfico de transbordo y la accesibilidad marítima constituyen las principales ventajas competitivas para este puerto. 


\section{CUADRO 1}

\section{EVOLUCIÓN DEL ÍNDICE «HUB» EN LOS PRINCIPALES PUERTOS} ESPAÑOLES* (2001-2011)

\begin{tabular}{|c|c|c|c|c|c|c|c|c|c|c|c|}
\hline Puerto & 2001 & 2002 & 2003 & 2004 & 2005 & 2006 & 2007 & 2008 & 2009 & 2010 & 2011 \\
\hline A Coruña & 0,11 & 0,00 & 0,02 & 0,04 & 0,01 & 0,17 & 0,00 & 0,16 & 0,05 & 0,07 & 0,02 \\
\hline Alicante & 0,08 & 0,10 & 0,00 & 0,00 & 0,08 & 0,05 & 0,00 & 0,02 & 0,04 & 0,27 & 1,13 \\
\hline Almería & 0,00 & 0,00 & 0,00 & 0,00 & 0,00 & 0,01 & 0,00 & 0,00 & 0,00 & 0,13 & 0,00 \\
\hline Avilés & 0,00 & 0,00 & 0,00 & 0,00 & 0,78 & 0,25 & 0,04 & 0,00 & 0,00 & 0,00 & 0,00 \\
\hline Algeciras & 36,84 & 13,69 & 47,36 & 49,85 & 51,97 & 55,45 & 58,43 & 58,91 & 54,96 & 52,21 & 58,88 \\
\hline Cádiz & 0,05 & 3,20 & 2,83 & 0,57 & 0,80 & 2,97 & 0,00 & 0,00 & 0,13 & 0,04 & 0,00 \\
\hline Barcelona & 0,00 & 0,00 & 14,80 & 14,50 & 18,81 & 22,74 & 24,33 & 24,25 & 18,07 & 17,49 & 16,71 \\
\hline Bilbao & 0,00 & 0,11 & 1,72 & 3,52 & 4,10 & 3,07 & 2,92 & 1,88 & 2,19 & 1,25 & 1,32 \\
\hline Cartagena & 0,00 & 0,13 & 0,17 & 0,04 & 0,02 & 0,09 & 0,01 & 0,50 & 0,03 & 0,39 & 0,45 \\
\hline Castellón & 0,00 & 0,00 & 0,00 & 0,04 & 0,59 & 0,11 & 0,01 & 0,06 & 0,00 & 0,15 & 0,45 \\
\hline Ceuta & 0,00 & 41,22 & 37,08 & 33,77 & 28,56 & 44,67 & 44,74 & 46,45 & 31,88 & 44,78 & 0,02 \\
\hline Ferrol & 0,00 & 5,97 & 0,00 & 0,01 & 0,00 & 0,34 & 0,12 & 0,35 & 0,44 & 0,43 & 0,16 \\
\hline Gijón & 0,01 & 0,09 & 0,00 & 0,00 & 0,36 & 0,83 & 1,30 & 2,39 & 3,36 & 4,86 & 5,37 \\
\hline Huelva & 0,00 & 1,44 & 0,06 & 0,00 & 0,00 & 0,57 & 0,48 & 0,32 & 0,78 & 1,87 & 6,00 \\
\hline Las Palmas & 26,31 & 33,11 & 43,43 & 49,58 & 50,96 & 53,29 & 55,05 & 57,92 & 51,19 & 55,06 & 57,47 \\
\hline Málaga & 0,00 & 0,00 & 0,02 & 17,06 & 43,97 & 58,20 & 60,91 & 55,49 & 30,13 & 36,88 & 68,90 \\
\hline Pontevedra & 0,00 & 0,09 & 0,00 & 0,05 & 0,00 & 0,03 & 0,56 & 0,10 & 0,02 & 0,74 & 2,07 \\
\hline Melilla & 0,00 & 0,00 & 0,00 & 0,00 & 0,00 & 0,00 & 0,00 & 0,17 & 0,00 & 0,00 & 0,00 \\
\hline Palma & 0,00 & 0,00 & 0,00 & 0,00 & 0,00 & 0,00 & 0,00 & 0,00 & 0,00 & 0,00 & 0,00 \\
\hline Pasaia & 0,00 & 0,00 & 0,00 & 0,00 & 0,00 & 0,00 & 0,00 & 0,00 & 0,00 & 0,01 & 0,00 \\
\hline S.C. Tenerife & 0,01 & 1,06 & 0,03 & 2,21 & 2,82 & 2,04 & 2,17 & 0,93 & 2,18 & 2,05 & 1,21 \\
\hline Santander & 0,00 & 0,03 & 0,01 & 0,04 & 0,08 & 0,40 & 0,00 & 0,11 & 0,05 & 0,12 & 0,07 \\
\hline Sevilla & 0,00 & 0,00 & 0,00 & 0,00 & 0,01 & 0,00 & 0,00 & 0,00 & 0,12 & 0,00 & 0,00 \\
\hline Tarragona & 0,00 & 9,19 & 8,26 & 9,21 & 8,37 & 8,66 & 10,66 & 12,97 & 18,21 & 18,87 & 16,69 \\
\hline Valencia & 14,05 & 22,91 & 27,05 & 26,24 & 27,97 & 27,52 & 26,89 & 45,38 & 53,89 & 56,98 & 56,04 \\
\hline Vigo & 0,13 & 2,15 & 2,94 & 4,01 & 1,66 & 3,43 & 2,85 & 4,89 & 5,69 & 5,87 & 8,58 \\
\hline V. Arousa & 0,00 & 0,00 & 0,00 & 0,00 & 0,00 & 0,00 & 0,00 & 0,35 & 2,58 & 0,96 & 3,68 \\
\hline
\end{tabular}

NOTA: * Entendemos como principales puertos aquellos que superan 1 millón de TEUs anuales para 2011.

FUENTE: Elaboración propia a partir de los Anuarios Estadísticos de Puertos del Estado. 
El Cuadro 1 nos muestra la evolución del índice HUB en los principales puertos españoles a lo largo de la última década. A partir de los datos de Puertos del Estado, hemos construido este ratio como el cociente entre el tráfico de transbordo y el total de tráfico de mercancías en el puerto. Este indicador nos muestra los principales puertos HUB del sistema español, donde destacan claramente los puertos de Algeciras, Las Palmas, Málaga y Valencia. Tras ellos, nos encontramos con los puertos de Barcelona y Tarragona. Casos ya mencionados como los de Valencia, Las Palmas o Algeciras nos llevan a la hipótesis de que los puertos dedicados mayoritariamente al tráfico de transbordo se enfrentan a escenarios más competitivos que aquellos que no lo hacen.

Profundizando en el tráfico de transbordo, vemos cómo este es parte importante los movimientos de tráfico de contenedores en algunos puertos. En todos los casos analizados, vemos la evolución positiva del índice HUB desde 2001 hasta 2011. En concreto, puertos como el de Málaga, Valencia o Las Palmas han practicado un incremento muy significativo, haciendo depender su actividad económica en gran parte de un sector altamente competitivo. Los costes de la estiba en España, pese a haber disminuido, continúan siendo altos. Este hecho constituye la queja principal de las compañías de transporte de contenedores y aparece frecuentemente como principal motivación expuesta por las navieras a la hora de plantearse escoger puertos competidores. Este es el caso de MSC, compañía que ha derivado durante 2013 entre 200.000 y 300.000 TEUs de Valencia a Sines, en Portugal, donde la mano de obra es más competitiva, derivado sin duda de un nivel de vida menos boyante ${ }^{28}$. De hecho, el puerto de Sines creció un 76 por 100, en gran parte gracias a los desvíos de Valencia.

- Tercer nivel de competencia: puertos gate. Otra de las fuentes de competencia que podemos identificar es la proveniente de aquellos grandes puertos que compiten por ser puerta de entrada de importantes zonas comerciales (conocidos como puerto gate). Este hecho supone una lucha por lo que podría considerarse como tráfico cautivo de gran alcance o de tráfico de transbordo marítimo-terrestre. En este caso, los factores de competitividad, como las conexiones terrestres, los costes de los factores productivos, la calidad de la tecnología, etcétera, son elementos fundamentales a la hora de seleccionar una u otra alternativa (NG, 2006). En el caso de los puertos del norte de Europa, desde Le Havre a Hamburgo, puede verse cómo todos compiten por convertirse en la puerta de entrada de mercancías a las zonas centroeuropeas (Notteboom, 1997). En este mismo contexto, la existencia de ríos navegables como el Rhin influyen en este nivel de competencia. Igualmente, González-Laxe (2012) recoge cómo la competencia de grandes puertos se ve intensificada tanto en los periodos de expansión como en los de crisis.

\footnotetext{
${ }^{28}$ MOLERO, D. (2014) y NAUCHER GLOBAL (2014).
} 
CUADRO 2

EVOLUCIÓN DE TRÁFICOS DE LOS PRINCIPALES PUERTOS ESPAÑOLES. RANKING POR TRÁFICO DE MERCANCÍA GENERAL EN 2011. CARGA Y PASAJEROS

\begin{tabular}{|c|c|c|c|c|}
\hline & $\begin{array}{c}\text { Tráfico de } \\
\text { mercancía } \\
\text { general } \\
(2011)\end{array}$ & $\begin{array}{c}\text { Tráfico de } \\
\text { pasajeros } \\
(2011)\end{array}$ & $\begin{array}{l}\text { \% evolución } \\
\text { tráfico de } \\
\text { mercancía } \\
\text { general } \\
(2001-2011)\end{array}$ & $\begin{array}{l}\text { \% evolución } \\
\text { tráfico de } \\
\text { pasajeros } \\
(\mathbf{2 0 0 1 - 2 0 1 1 )}\end{array}$ \\
\hline Valencia & 55.831 .955 & 601.462 & 210,37 & 119,98 \\
\hline B. Algeciras & 52.235 .153 & 3.247 .939 & 91,03 & $-24,02$ \\
\hline Barcelona & 28.759 .658 & 2.327 .528 & 58,58 & 61,29 \\
\hline Las Palmas & 16.212 .279 & 1.078 .396 & 98,19 & 41,14 \\
\hline Bilbao & 9.865 .576 & 137.264 & 24,57 & $-93,95$ \\
\hline Palma & 5.348 .283 & 1.582 .346 & 25,57 & 51,96 \\
\hline S.C. de Tenerife & 4.534 .191 & 1.547 .513 & $-3,53$ & 4,18 \\
\hline Málaga & 4.373 .425 & 720.919 & 958,79 & 15,60 \\
\hline Tarragona & 3.755 .550 & 752 & 289,52 & $-36,97$ \\
\hline Vigo & 3.456 .496 & 244.030 & 17,18 & 363,53 \\
\hline Sevilla & 2.243 .245 & 2.461 & 36,49 & $-7,34$ \\
\hline Castellón & 2.137 .688 & 586 & 151.25 & $-99,89$ \\
\hline Cádiz & 1.963 .140 & 389.983 & $-23,78$ & $-88,02$ \\
\hline Pasaia & 1.949 .180 & 0 & 16,50 & $-100,00$ \\
\hline Santander & 1.683 .387 & 219.191 & 66,75 & 67,93 \\
\hline Gijón & 1.465 .841 & 57.004 & 155.80 & $-97,53$ \\
\hline Alicante & 1.430 .913 & 329.647 & $-6,85$ & 17,08 \\
\hline Avilés & 1.244 .979 & 0 & 32,97 & $-100,00$ \\
\hline A Coruña & 1.227 .459 & 125.367 & 188,76 & 365,10 \\
\hline Cartagena & 1.139 .267 & 88.081 & 104,46 & $-94,42$ \\
\hline Pontevedra & 958.866 & 0 & 2,27 & $-100,00$ \\
\hline Ceuta & 865.427 & 1.863 .128 & 6,40 & $-23,83$ \\
\hline Melilla & 762.617 & 642.733 & 28,96 & 134,02 \\
\hline Ferrol & 661.718 & 9.422 & 19,15 & - \\
\hline Almería & 568.544 & 947.554 & 34,65 & $-13,36$ \\
\hline Huelva & 454.166 & 15.273 & $-51,67$ & $4.432,05$ \\
\hline V. de Arousa & 271.736 & 3.126 & 1,56 & $-44,52$ \\
\hline
\end{tabular}

FUENTE: Elaboración propia a partir de los Anuarios de Puertos del Estado. 
En España, nos encontramos con una realidad similar a la del norte europeo. Es el caso de la competencia de puertos en el Mediterráneo, en concreto entre Barcelona y Valencia. El espectacular crecimiento del segundo en términos de tráfico de mercancías a lo largo de la década, como muestra el Cuadro 2, le ha llevado a situarse en las primeras posiciones del tráfico de mercancías en España, con unos muy altos niveles de tráfico de transbordo. Ambos puertos suponen un claro ejemplo como competidores por el hinterland de Madrid y Aragón (donde se sitúa la plataforma logística PLAZA, la mayor de Europa).

- Cuarto nivel de competencia: regiones de influencia. Entre puertos grandes con zonas de influencia cercanas. Los puertos modernos han dejado en general de tener una situación de monopolio para el tráfico cautivo de sus regiones de influencia o hinterlands, ya que el desarrollo de cadenas integradas de transporte ha aumentado el tamaño de estas zonas de influencia (García y Sánchez, 2006). Es el caso de puertos como Tarragona o Barcelona en cuanto al tráfico de mercancías, o Las Palmas y Sta. Cruz de Tenerife si consideramos el tráfico de cruceros.

Si bien es cierto que tiempo atrás la especialización de los puertos podía ser un claro ejemplo diferenciador y por tanto de reducción de la competencia en determinados tráficos, la containerizacion del tráfico marítimo ha llevado no solo a una mayor integración de las cadenas de suministro (Rodrigue, 2013) -y por tanto a una reducción de los tiempos totales en puertos-, sino al establecimiento de un marco de competencia común para la mayoría de los puertos, reforzando los niveles anteriormente mencionados.

El Cuadro 3 muestra claramente el hecho mencionado. El índice de contenedorización ha sido construido a partir del volumen de tráfico desplazado en contenedores con relación al tráfico total. Si bien a principios de siglo el volumen medio de contenedores en puertos suponía alrededor de un 30 por 100, a finales de la década alcanzaba el 44 por 100. En puertos como Alicante, Algeciras, Castellón, Las Palmas, Málaga o Valencia este índice supera ampliamente el 80 por 100 a finales de 2011. Este hecho supone que los puertos se centran cada vez más en un tráfico comparable y, por tanto, en el que se percibe de manera más directa la competencia existente bajo los niveles mencionados. 


\section{CUADRO 3}

EVOLUCIÓN DEL ÍNDICE DE CONTENEDORIZACIÓN EN LOS PRINCIPALES PUERTOS ESPAÑOLES (2001-2011)

\begin{tabular}{|c|c|c|c|c|c|c|c|c|c|c|c|}
\hline & 2001 & 2002 & 2003 & 2004 & 2005 & 2006 & 2007 & 2008 & 2009 & 2010 & 2011 \\
\hline A Coruña & 0,00 & 0,00 & 0,00 & 0,00 & 0,00 & 2,00 & 8,00 & 7,00 & 9,00 & 8,00 & 5,00 \\
\hline Alicante & 64,46 & 62,90 & 66,53 & 68,42 & 65,63 & 67,42 & 68,53 & 66,56 & 76,03 & 85,48 & 89,13 \\
\hline Almería & 0,06 & 0,06 & 0,03 & 0,07 & 0,03 & 0,07 & 0,02 & 0,48 & 2,68 & 5,77 & 10,06 \\
\hline Avilés & 0,05 & 6,71 & 7,57 & 6,80 & 8,20 & 4,98 & 4,84 & 4,83 & 2,20 & 0,00 & 0,00 \\
\hline Algeciras & 88,33 & 87,86 & 89,69 & 89,29 & 89,67 & 90,24 & 89,99 & 90,06 & 89,52 & 88,76 & 91,19 \\
\hline Cádiz & 32,06 & 38,73 & 37,16 & 34,10 & $\mathbf{3 7 , 9 3}$ & 42,52 & 50,07 & 48,18 & 50,08 & 52,96 & 45,73 \\
\hline Barcelona & 74,05 & 71,74 & 73,35 & 74,02 & 73,12 & 71,07 & 72,24 & 72,01 & 67,49 & 69,08 & 69,04 \\
\hline Bilbao & 58,02 & 59,20 & 58,08 & 57,93 & 58,85 & 59,92 & $\mathbf{5 9 , 7 5}$ & 63,57 & 65,35 & 60,30 & 61,62 \\
\hline Cartagena & 12,50 & 65,62 & 55,03 & 43,16 & 46,47 & 43,60 & 50,65 & 50,34 & 80,96 & 79,06 & 76,55 \\
\hline Castellón & 33,44 & 33,82 & 41,56 & 47,37 & 48,44 & 61,09 & 72,54 & 68,65 & 59,83 & 74,14 & 80,59 \\
\hline Ceuta & 12,70 & 7,10 & 6,42 & 7,24 & 7,96 & 6,93 & 7,43 & 7,68 & 6,23 & 5,19 & 7,67 \\
\hline Ferrol & 0,05 & 0,08 & 0,16 & 0,09 & 0,17 & 1,37 & 5,86 & 0,10 & 0,76 & 0,85 & 0,85 \\
\hline Gandía & 0,00 & 0,10 & 0,29 & 0,04 & 0,01 & 0,00 & 0,31 & 0,24 & 0,05 & 0,00 & 1,08 \\
\hline Gijón & 32,11 & 17,36 & 21,36 & 17,04 & 13,04 & 14,57 & 23,05 & 36,60 & 47,72 & 45,60 & 30,13 \\
\hline Huelva & 0,00 & 0,00 & 0,00 & 0,00 & 0,00 & 0,00 & 0,00 & 0,00 & 0,00 & 0,00 & 1,37 \\
\hline Las Palmas & 70,07 & 72,18 & 78,48 & 81,38 & 82,29 & 84,09 & 84,60 & 87,12 & 83,70 & 85,41 & 84,91 \\
\hline Málaga & 4,08 & 3,22 & 1,49 & 56,58 & 83,49 & 89,26 & 89,72 & 85,70 & 59,49 & 68,37 & 89,87 \\
\hline Pontevedra & 28,87 & 34,83 & 31,61 & 32,01 & 32,86 & 36,58 & 42,58 & 67,55 & 63,41 & 58,54 & 65,43 \\
\hline Melilla & 19,44 & 19,73 & 19,53 & 20,07 & 19,27 & 22,31 & 23,45 & 24,11 & 24,83 & 22,05 & 27,20 \\
\hline Palma & 25,67 & 22,91 & 21,19 & 25,82 & 18,29 & 16,07 & 11,75 & 8,90 & 8,75 & 6,91 & 5,04 \\
\hline Sagunto & 8,14 & 6,70 & 7,08 & 9,66 & 8,92 & 2,82 & 1,78 & 4,10 & 15,31 & 18,94 & 15,89 \\
\hline Tenerife & 60,20 & 59,16 & 58,33 & 58,08 & 59,94 & 58,92 & 587,66 & 57,27 & 57,88 & 58,42 & 55,41 \\
\hline Santander & 2,15 & 9,39 & 9,13 & 0,19 & 0,11 & 0,14 & 0,35 & 0,55 & 1,91 & 0,80 & 1,19 \\
\hline Sevilla & 43,12 & 40,58 & 41,79 & 44,42 & 45,41 & 42,61 & 49,10 & 48,67 & 52,49 & 56,39 & 56,60 \\
\hline Tarragona & 33,61 & 39,64 & 36,75 & 15,00 & 6,87 & 7,47 & 24,16 & 28,09 & 78,46 & 78,39 & 68,18 \\
\hline Valencia & 88,39 & 89,47 & 89,47 & 89,65 & 88,76 & 88,12 & 88,11 & $\mathbf{9 0 , 4 5}$ & 89,74 & 91,54 & $\mathbf{9 0 , 4 5}$ \\
\hline Vigo & 47,35 & 52,01 & 52,14 & 57,71 & 60,51 & 59,35 & 56,32 & 57,65 & 64,07 & 64,63 & 66,94 \\
\hline V. Arousa & $\mathbf{0 , 0 0}$ & 0,00 & 0,00 & 0,00 & 0,00 & 0,28 & $\mathbf{0 , 0 3}$ & 43,94 & 50,13 & 2,83 & 39,13 \\
\hline
\end{tabular}

FUENTE: Elaboración propia a partir de los Anuarios Estadísticos de Puertos del Estado. 


\subsection{Competencia en el puerto}

- Quinto nivel de competencia: tráfico cautivo. Entre terminales dentro del mismo puerto, que a su vez se enmarcan en zonas de influencia sin intercesiones con otros puertos. Como destacan Villaverde et al. (2011), en España la mayor parte del tráfico exterior de las empresas ubicadas en la provincia lo hace a través de la fachada marítima más próxima. En estos casos nos enfrentamos a una situación de cuasi-monopolio que invita al estudio de opciones para el fomento de la intensidad competitiva (Heaver, 1995). Un caso evidente podría ser el de alguna isla relativamente grande con un solo puerto comercial importante para atender el tráfico cautivo. Si los puertos son grandes y contienen más de una terminal, el fomento de la competencia entre ellas, por el tráfico cautivo del hinterland, se hace indispensable para controlar los niveles de tarifas de los servicios, de manera que su influencia en los precios de los bienes no sea excesiva. Indudablemente, los procesos de reforma que han llevado aparejados, tanto la liberalización de servicios como la aparición de operadores privados ha contribuido a que exista competencia entre diferentes terminales de carga dentro de un mismo puerto, pero también se corre el peligro de algún tipo de acuerdo o colusión entre las propias terminales en términos de cuotas o precios. Un ejemplo interesante de este nivel de competencia podría ser el puerto de Las Palmas en la isla de Gran Canaria. Este puerto está compuesto por tres terminales de contenedores que compiten ente si para atender el tráfico cautivo.

- Sexto nivel de competencia: puertos pequeños. En puertos pequeños que no admiten más que una terminal para atender el tráfico cautivo. Como recoge la Comisión europea (COM, 2013), las últimas tendencias en el campo de la logística y de los sistemas de distribución han atraído más servicios de valor añadido para las zonas portuarias, hecho que posee especial relevancia a la hora de establecer normas de competencia en los puertos y para los sistemas de tarificación. En el caso de estos puertos donde existe una única terminal, se hace forzosa la regulación económica de las tarifas de los servicios portuarios (Trujillo y Nombela, 1999). La literatura reconoce que el papel del regulador es indispensable en el control de la competencia, especialmente en estos últimos niveles, toda vez que no existan incentivos por parte de los operadores privados a coludir (cuarto nivel) o a no cumplir con las tarifas máximas estipuladas (De Langen y Pallis, 2006; Coto Millán e Inglada, 1999). Este riesgo se ve agravado por la posibilidad de la captura del regulador por parte del regulado. Como se comentó anteriormente, en España las autoridades portuarias ejercen la regulación económica, por tanto, a priori, podría haber posibilidades de que esto ocurriera dada la obvia cercanía del regulador y el regulado. 


\section{Competencia intermodal}

Hoy en día, alrededor del 40 por 100 del comercio intrarregional en Europa se realiza mediante las actuales rutas de transporte marítimo de corta distancia. Atendiendo a los datos del Centro para la Promoción en España del TMCD ${ }^{29}$, en España existen 34 servicios que conectan 43 puertos europeos en la costa cantábrica, y 35 servicios que relacionan 64 puertos europeos en la mediterránea, en los puertos de Santander, Bilbao, Gijón, Ferrol y Vigo en el océano Atlántico, y Barcelona, Tarragona, Castellón, Valencia y Cartagena en el mar Mediterráneo.

La UE tiene la intención de que esta cifra aumente. En concreto, se ha establecido el objetivo de trasladar un 30 por 100 de la mercancía de corredores por carretera superiores a los 300 kilómetros a otros modos para el 2030, y mucho menos un 50 por 100 en 2050 (COM, 2011b). Podemos resumir los argumentos para apoyar el transporte marítimo principalmente en dos: mejoras medioambientales y fomento de la competencia. En cuanto al primero, la UE ha cuantificado el daño que el transporte por carretera supone para la sociedad en términos de costes externos. Así pues, externalidades tales como la congestión, polución y otros aspectos medioambientales motivaron -como quedó señalado en el apartado anterior- el desarrollo de una política de transporte socialmente responsable (Medda y Trujillo, 2009). Por otra parte, el segundo argumento gira en torno a la necesidad de fomentar la competencia en el mercado del transporte de mercancías, tradicionalmente desequilibrado por modos.

En términos de competencia intermodal, el transporte por carretera absorbe alrededor de la mitad del mercado de transporte de mercancías. A pesar de los esfuerzos y las políticas analizadas más adelante, los obstáculos a una competencia efectiva en el mercado continúan existiendo (COM, 2011b). En 1995, el transporte por carretera suponía el 42,1 por 100 del total del mercado en la UE-27, y el transporte marítimo un 37,5 por 100 . En 2009, estas cifras habían cambiado a 46,6 y 36,8 por 100 , respectivamente. Esto es, la diferencia entre ambos modos se ha visto incrementada de un 4,6 al 9,8 por 100. En el caso exclusivamente español, estas cifras aumentan significativamente en cuanto al tráfico interior se refiere. El Gráfico 1 muestra la evolución de las cuotas modales en el transporte de mercancías en España durante los últimos años.

Los datos muestran como, si bien se percibe un ligero incremento del modo marítimo (13,01 por 100 en 2011), la carretera (84,42 por 100) sigue constituyendo por mucho el principal modo en cuanto al transporte de mercancías se refiere, donde el modo aéreo $(0,2$ por 100$)$ y el ferrocarril $(2,56$ por 100$)$ juegan un papel mucho menor. Por tanto, los principales objetivos de la política de transporte marítimo europeo pueden ser resumidos en 1) la necesidad de facilitar la apertura de los mercados de transportes a la competencia libre y no distorsionada y 2) ofrecer soluciones de transporte medioambientalmente sostenibles (COM, 2011b).

29 www.shortsea.es. 


\section{GRÁFICO 1 \\ REPARTO MODAL DEL TRÁFICO INTERIOR DE MERCANCÍAS SEGÚN MODO DE TRANSPORTE EN ESPAÑA (2007-2011)}

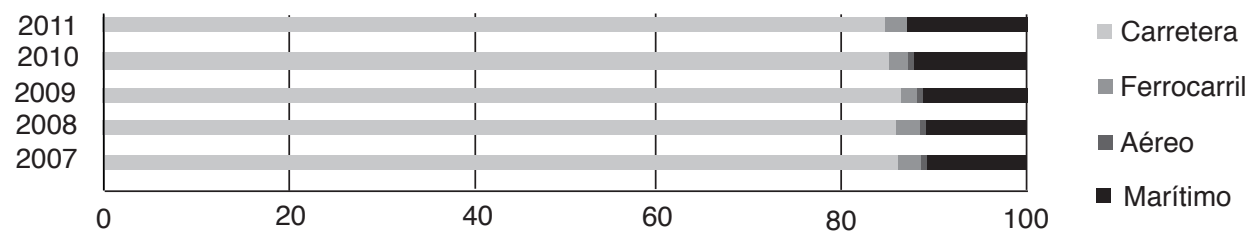

FUENTE: Ministerio de Hacienda (2014).

A estos hechos se une que en el continente europeo alrededor del 70 por 100 de la producción industrial se encuentra a 150-200 kilómetros de la costa (Paixão y Marlow, 2002). Al mismo tiempo, de acuerdo a las estadísticas del Eurostat (2011), más de 205 millones de personas viven en regiones costeras en Europa, esto es, el 41 por 100 de la población de la UE. Más de 1.200 puertos comerciales operan a lo largo de los 70.000 kilómetros de costas europeas (COM, 2013a).

Por todo ello, la UE ha desarrollado en los últimos años una serie de políticas con el objetivo de alcanzar una verdadera competencia intermodal en el sector. Programas tales como la Acción Piloto para el Transporte Combinado (APTC), Marco Polo I y II y la Red Trans-Europea de Transportes (RTE-T) han sido diseñados-considerando ciertas diferencias entre ellos en cuanto a objetivos específicos, tiempos y aspectos formales- para promocionar modos de transporte socialmente preferidos, además de la intermodalidad de los mismos ${ }^{30}$. En concreto, APTC, Marco Polo I y II se han centrado en la promoción del TMCD a través de la concesión de ayudas a aquellas compañías que transfiriesen mercancía desde la carretera.

En España, el Ministerio de Fomento (2011) sugiere promocionar corredores de alrededor de 800 kilómetros que se encuentren en competencia directa con la carretera, con el objeto de instaurar rutas intermodales (carretera-mar-carretera) que sean capaces de competir con el transporte único terrestre. La idea es que el embarque de contenedores rodantes $(R o-R o)$ permitan la descongestión de la red viaria europea. En este caso es fundamental que los puertos funcionen de manera muy eficiente en términos de tiempo para que no se creen cuellos de botella en la cadena de transporte (Suárez-Alemán et al., 2014). Por tanto, la competencia entre puertos se establece en términos de tiempo/precio/costes externos. Ejemplos de estas líneas de TMCD son la de Barcelona-Génova, la de Barcelona-Civittavechia y la de Valencia-Livorno. Además surge la oportunidad para los puertos de relajar las expectativas de convertirse en grandes puertos, que en muchos casos se ha trasladado

\footnotetext{
${ }^{30}$ SUÁREZ-ALEMÁN et al. (2014a, 2014b) presentan una revisión más detallada de estos programas.
} 
en una guerra por tener las infraestructuras más avanzadas. Es decir, con el SSS, los puertos se pueden especializar en atender este tipo de tráfico con instalaciones adecuadas para los buques Ro-Ro .

\section{Análisis integral de competencia en el sistema portuario español}

A partir de las secciones anteriores, podemos plantear un análisis de las diferentes fuentes y niveles de competencia analizados para los principales puertos españoles. Con este objeto, el Cuadro 4 recoge los criterios por los cuales han sido valorados como alto, medio o bajo grado de potencial competencia cada uno de los niveles anteriormente analizados.

\section{CUADRO 4}

CRITERIOS PARA LA VALORACIÓN DEL GRADO DE COMPETENCIA POTENCIAL

\begin{tabular}{|c|c|c|c|c|}
\hline Nivel & Concepto & Bajo & Medio & Alto \\
\hline 1 & Concesiones & \multicolumn{3}{|c|}{$\begin{array}{l}\text { Se considera un nivel medio para todos los puertos basados en la legislación } \\
\text { española, que afecta a todos por igual y que ha presentado ciertos riesgos } \\
\text { analizados en la sección } 2\end{array}$} \\
\hline 2 & Trasbordo & Índice HUB <10 & Índice HUB 10-49 & Índice HUB $\geq 50$ \\
\hline 3 & Gate & $\begin{array}{l}\text { Mercancía transportada } \\
\text { por ferrocarril desde el } \\
\text { puerto } \\
<500.000 \text { TEUS/año }\end{array}$ & $\begin{array}{l}\text { Mercancía transportada } \\
\text { por ferrocarril desde el } \\
\text { puerto } \\
500.000-999.999 \text { TEUS/ } \\
\text { año }\end{array}$ & $\begin{array}{l}\text { Mercancía transportada } \\
\text { por ferrocarril desde el } \\
\text { puerto } \\
\geq 1.000 .000 \text { TEUS/año }\end{array}$ \\
\hline 4 & Hinterland & $\begin{array}{l}\text { Con más de } 17 \text { puertos } \\
\text { españoles en un radio } \geq \\
\text { a } 600 \mathrm{kms}\end{array}$ & $\begin{array}{l}\text { Con } 16 \text { ó } 17 \text { o más puer- } \\
\text { tos situados en un radio } \\
\text { entre } 400 \text { y } 599 \text { kms } \\
\text { y menos de } 6 \text { puertos } \\
\text { situados en un radio < a } \\
400 \mathrm{~km} \text {. }\end{array}$ & $\begin{array}{l}\text { Con } 6 \text { o más puertos } \\
\text { situados en un radio } \\
\text { inferior a los } 400 \mathrm{~km} \text {. }\end{array}$ \\
\hline 5 & Cautivo & $\begin{array}{l}\text { Islas con población supe. } \\
\text { rior a los } 500.000 \text { habi- } \\
\text { tantes. }\end{array}$ & $\begin{array}{l}2 \text { o menos terminales } \\
\text { compitiendo por tráficos } \\
\text { similares. }\end{array}$ & $\begin{array}{l}\text { Más de dos terminales } \\
\text { compitiendo por tráficos } \\
\text { similares. }\end{array}$ \\
\hline 6 & Tamaño & $\begin{array}{l}\text { TEUS/año } \\
<1.000 .000\end{array}$ & $\begin{array}{l}\text { TEUS/año } \\
1.000 .000-4.999 .999\end{array}$ & $\begin{array}{l}\text { TEUS/año } \\
\geq 5.000 .000\end{array}$ \\
\hline 7 & Intermodal & $\begin{array}{l}\text { Sin posibilidad de cone- } \\
\text { xión por carretera o } \\
\text { ferrocarril a las redes eu- } \\
\text { ropeas } \\
\text { (Islas, Ceuta y Melilla) }\end{array}$ & $\begin{array}{l}\text { Conconexionesnodirec- } \\
\text { tas a la red europea de } \\
\text { carreteras o líneas de } \\
\text { alta velocidad }\end{array}$ & $\begin{array}{l}\text { Conectados directamen- } \\
\text { te a la red europea de ca- } \\
\text { rreteras o con conexiones } \\
\text { de alta velocidad }\end{array}$ \\
\hline
\end{tabular}

FUENTE: Elaboración propia. 
La elección ad hoc de las diferentes categorías por cada nivel pretende cuantificar de manera descriptiva el potencial riesgo de falta de competencia en los principales puertos españoles analizados. A partir de los criterios establecidos, el Cuadro 5 refleja los resultados de su aplicación a los principales puertos españoles en cuanto al tráfico de mercancías se refiere.

\section{CUADRO 5}

\section{ANÁLISIS INTEGRAL DE LOS GRADOS DE COMPETENCIA POTENCIAL EN LOS PRINCIPALES PUERTOS ESPAÑOLES EN CUANTO AL TRÁFICO DE MERCANCÍAS}

\begin{tabular}{|c|c|c|c|c|c|c|c|}
\hline \multirow{2}{*}{ Puerto } & Nivel 1 & Nivel 2 & Nivel 3 & Nivel 4 & Nivel 5 & Nivel 6 & Nivel 7 \\
\hline & Concesiones & Trasbordo & Gate & Hinterland & Cautivo & Tamaño & Intermodal \\
\hline A Coruña & Medio & Bajo & Medio & Alto & Medio & Medio & Medio \\
\hline Alicante & Medio & Bajo & Bajo & Medio & Medio & Medio & Alto \\
\hline Almería & Medio & Bajo & Bajo & Alto & Medio & Bajo & Medio \\
\hline Avilés & Medio & Bajo & Bajo & Alto & Medio & Medio & Medio \\
\hline Algeciras & Medio & Alto & Bajo & Alto & Alto & Alto & Medio \\
\hline Barcelona & Medio & Alto/Medio & Alto & Bajo & Alto & Alto & Alto \\
\hline Bilbao & Medio & Bajo & Medio & Bajo & Medio & Alto & Alto \\
\hline Cádiz & Medio & Bajo & Bajo & Bajo & Medio & Bajo & Medio \\
\hline Cartagena & Medio & Bajo & Bajo & Medio & Medio & Medio & Medio \\
\hline Castellón & Medio & Bajo & Bajo & Alto & Medio & Medio & Alto \\
\hline Ceuta & Medio & Bajo & Bajo & Bajo & Medio & Medio & Bajo \\
\hline Ferrol & Medio & Bajo & Bajo & Alto & Medio & Bajo & Medio \\
\hline Gijón & Medio & Bajo/Medio & Alto & Alto & Medio & Medio & Medio \\
\hline Huelva & Medio & Bajo/Medio & Bajo & Bajo & Medio & Bajo & Medio \\
\hline Las Palmas & Medio & Alto & Bajo & Bajo & Bajo & Alto & Bajo \\
\hline Málaga & Medio & Alto & Bajo & Alto & Medio & Medio & Alto \\
\hline Melilla & Medio & Bajo & Bajo & Bajo & Medio & Bajo & Bajo \\
\hline Palma & Medio & Bajo & Bajo & Bajo & Bajo & Alto & Bajo \\
\hline Pasaia & Medio & Bajo & Bajo & Alto & Medio & Medio & Medio \\
\hline Pontevedra & Medio & Bajo & Bajo & Bajo & Medio & Medio & Medio \\
\hline S.C. Tenerife & Medio & Bajo & Bajo & Bajo & Bajo & Medio & Bajo \\
\hline Santander & Medio & Bajo & Medio & Medio & Medio & Medio & Medio \\
\hline Sevilla & Medio & Bajo & Bajo & Bajo & Medio & Medio & Alto \\
\hline Tarragona & Medio & Alto/Medio & Alto & Bajo & Alto & Medio & Alto \\
\hline Valencia & Medio & Alto & Alto & Alto & Alto & Alto & Alto \\
\hline Vigo & Medio & Bajo/Medio & Bajo & Bajo & Medio & Medio & Medio \\
\hline V. Arousa & Medio & Bajo & Bajo & Alto & Medio & Bajo & Medio \\
\hline
\end{tabular}

FUENTE: Elaboración propia. 
A partir de los criterios establecidos, el Cuadro 5 refleja los resultados de su aplicación a los principales puertos españoles en cuanto al tráfico de mercancías se refiere. De este modo, podemos identificar determinados casos donde la competencia potencial se percibe realmente baja. Atendiendo a este simple análisis de competencia descriptivo y multicriterio, observamos como ciertos puertos -dadas sus estructuras de tráfico, número de competidores cercanos, estructura de las terminales, mercados que abastecen y posición geográfica- presentan características que pueden favorecer a la existencia de prácticas restrictivas de la competencia. Así, destacan algunos puertos del sur español como los de Cádiz, Cartagena, Ceuta, Huelva y Melilla; las islas (Palma y Santa Cruz de Tenerife) y norte (Vigo y Pontevedra). En estos puertos los diferentes niveles de competencia se perciben como bajos en la mayoría de los casos, lo que nos debería llevar a prestar especial atención al grado de competencia en estas infraestructuras. En estos casos, la competencia por el puerto/terminal a través de procesos de concesión adecuados se torna especialmente relevante, toda vez que otras fuentes de competencia más directas quedan comprometidas. Igualmente, resulta necesario recordar la competencia internacional que perciben los puertos españoles. Fuera de la presión competitiva entre los puertos nacionales, los puertos gallegos se enfrentan a una dura competencia en la cornisa atlántica que por el momento no han podido responder y que ha llevado a un importante traspaso del tráfico - proveniente de Vigo, principalmente- hacia el puerto portugués de Leixoes en Oporto ${ }^{31}$. Al mismo tiempo, ante las necesidades de fomento de la competencia en los puertos de la vertiente norte española deben también contemplarse posibles mejoras en los accesos a las infraestructuras portuarias y la conectividad terrestre de estas regiones ya que, de producirse, supondrían directamente una importante intensificación de la competencia entre sus puertos ${ }^{32}$. En cuanto a los grandes puertos, como señala González Laxe (2012), su competencia se acrecienta tanto en periodos de expansión como de crisis. Atendiendo a los casos de Algeciras, Barcelona, Valencia o Las Palmas, el autor comenta cómo sus evoluciones y tensiones competitivas han respondido a aspectos cualitativos tales como la capacidad de atracción de los agentes marítimos, los procesos de intermodalidad y la potencialidad de su base logística y de inserción en las cadenas de suministro global. En este sentido, los puertos de Barcelona y Valencia han apostado por la inclusión de los operadores ferroviarios dentro de la infraestructura portuaria (Terminales BEST y TERCAT en el Puerto de Barcelona) y, después de aprovechar las ayudas comunitarias para profundizar en su competitividad intermodal ${ }^{33}$, continúan hoy con distintos planes

\footnotetext{
31 El crecimiento del puerto de Leixoes, cuyos tráficos han aumentado por encima del 10 por 100 en 2013 , parece ser la explicación principal de los malos resultados de los puertos gallegos que, pese al magnífico ejercicio de Ferrol, presentaban una bajada media de 0.2 puntos sobre su aportación a la red portuaria española en 2013. (12/05/2014),http://www.economiadigital.es/gles/notices/2014/05/los_puertos_gallegos_pierden_peso_en_espana_ en_todos_los_traficos_36527.php.

32 (10/09/2007), http://www.lavozdegalicia.es/opinion/2007/09/10/0003_6128614.htm?utm_source=buscavoz \&utm_medium=buscavoz

33 La Autoridad Portuaria de Valencia recurría en 2008 a la línea de financiación contemplada en el programa europeo Marco Polo II. (03/12/2008), http://elpais.com/diario/2008/12/03/cvalenciana/1228335491_850215.html_
} 
de acceso a otros medios de transporte ${ }^{34}$. Por su parte el Puerto de Las Palmas en Gran Canaria continúa atrayendo a navieras de todo el mundo por su posición geoestratégica para el comercio con África, compensando así el importante volumen de tráfico perdido con la marcha de Maersk, que en 2013 se trasladaba al Puerto de Algeciras ${ }^{35}$. Es en este puerto donde la naviera controla la principal terminal de contenedores, y se enfrenta a unos menores costes portuarios.

Por último, no debe olvidarse que esta matriz recoge los potenciales perjuicios sobre la competencia en los puertos estudiados. Sin embargo, existen otras prácticas restrictivas de la competencia que pueden presentarse fácilmente incluso en puertos donde los niveles de competencia potencial se presentan como realmente altos, pero donde los agentes coluden vulnerando la libre competencia. Es el caso de aquellas prácticas relacionadas con el pacto de precios en los servicios de transporte de mercancías, donde recientemente han destacados los casos de Valencia y Barcelona $^{36,37}$.

\section{Implicaciones de política económica}

Como se ha señalado, se pueden distinguir varias situaciones dentro de los distintos niveles de desarrollo. Hay puertos que debido a su escaso mercado no requieren más que una terminal general para todo tipo de mercancías y contenedores o en su caso alguna terminal especializada en graneles (competencia intraterminales). En este tipo de puertos, se puede introducir alguna forma de competencia por el mercado. Por ejemplo, pueden establecerse concursos públicos para que varias empresas compitan por el derecho a operar una terminal. Una vez adjudicada la terminal a una empresa, sería necesaria la introducción de regulación sobre los precios que este único operador privado cobra a los usuarios. La renovación periódica de estas concesiones introduciría incentivos a que el operador lograse ganancias de eficiencia que le situasen en la mejor posición posible para tratar de renovar la concesión.

Sin embargo, la necesidad de regular los precios estaría sujeta a la posible competencia entre puertos. Así, si hay puertos cercanos con los que se establezca una relación competitiva, la regulación de las tarifas de la terminal se haría menos

\footnotetext{
${ }^{34}$ (28/09/2012), http://www.vialibre-ffe.com/noticias.asp?not=9508.

35 En verano de 2014 el grupo holandés Spliethoff -en el que se integran firmas como BigLift Shippingpromocionaba el Puerto de Las Palmas como base logística de mercancías. (15/06/2014), http://www.laprovincia. es/las-palmas/2014/06/15/grupo-holandes-promociona-luz-base/614811.html

${ }^{36}$ En octubre de 2013, la Comisión Nacional de Competencia (CNC) impuso multas por un total de 43 millones de euros a asociaciones de transporte en el Puerto de Valencia, empresas concesionarias, la Autoridad Portuaria y al Gobierno de la región por pactar precios, servicios e indemnizaciones y de restringir la oferta de prestadores de servicio en el puerto de Valencia. (02/10/2013), http://economia.elpais.com/economia/2013/10/02/ actualidad/1380727953_186102.html

37 En enero de 2013, la CNC determinó la existencia de un cartel en el puerto de Barcelona entre los años 2006 y 2011. Según la CNC, las patronales de transportistas fijaban las tarifas y las condiciones comerciales, limitaban y controlaban la producción y repartían el mercado dentro de las instalaciones portuarias. La comisión acordó sanciones por encima de los 20 millones de euros (15/01/2013), http://ccaa.elpais.com/ccaa/2013/01/14/ catalunya/1358195908_638845.html.
} 
necesaria, ya que el propio mecanismo de mercado llevaría a que el operador de la terminal se viera obligado a limitar sus precios o correría el riesgo de perder demanda en favor de puertos rivales. En el caso de puertos de tamaño más grande parece razonable el fomento de competencia interterminales. Es decir, si el puerto se divide en varias terminales, de forma que éstas compitan entre sí, se reduciría la necesidad de regular los precios con los que operan las terminales, ya que éstos se determinarían en el mercado.

En términos generales, y en particular para las empresas concesionarias de terminales, en los puertos españoles se aplica una regulación por tarifa máxima (price cap). En algunas ocasiones este tipo de tarificación no es efectiva debido a la competencia entre terminales o entre puertos. La regulación se hace efectiva para el tráfico cautivo en puertos con una sola terminal. La introducción adicional de algún tipo de control de la eficiencia (regulación tipo revenue cap, $R P I-X$ ) podría ayudar a hacer más efectivo el sistema en su conjunto.

El impacto de la competencia internacional juega un papel ciertamente importante en la competitividad futura de los puertos españoles, especialmente aquellos grandes puertos con importantes niveles de tráfico de transbordo (puertos hubs) o para los grandes puertos de entrada (puertos gate). El que una ruta asiática decida hacer transbordo de mercancías en España, Italia o Portugal hacia las embarcaciones que navegan en la americana dependerá esencialmente de la fiabilidad y el coste. Este hecho hace que puertos como Algeciras, por ejemplo, estén empezando a sentir el impacto de otros como Tánger, más moderno y con menores tarifas. El consignatario no tiene barreras de salida para cambiar un puerto por otro.

Por tanto, el panorama portuario se vislumbra como un conjunto de empresas concesionarias privadas que funcionan con activos públicos en un ambiente relativamente competitivo. En este contexto, los aspectos de regulación tienen relativa importancia sobre todo para el caso del tráfico cautivo. El diseño correcto de los contratos de concesión para la introducción de participación privada y los sistemas de regulación de tarifas aparecen entonces como las piezas fundamentales de la nueva organización portuaria. Como se ha comentado anteriormente, la existencia de competencia es un factor que reduce sensiblemente la necesidad de una estricta regulación. En los casos en los que exista suficiente competencia, la propia disciplina del mercado obligaría a las empresas privadas que trabajan con concesiones en los puertos a limitar sus tarifas.

\section{Conclusiones}

El sistema portuario español ha experimentado a lo largo de los últimos años una serie de cambios tanto endógenos -reformulación del sistema, nueva legislacióncomo exógenos -el incremento de los niveles de contenedorización, el impacto de la crisis económica- que han dibujado un nuevo escenario. El gran volumen de mercancías así como la actividad económica que generan a su alrededor hacen de los puertos una unidad de análisis económica de especial relevancia. 
Aun con el reciente impacto de la crisis económica de finales de la década, la Comisión Europea establece que, partiendo incluso de hipótesis de crecimiento moderado, se espera que los volúmenes de carga aumenten en un 50 por 100 de aquí a 2030 y todavía más si se tiene en cuenta el rápido crecimiento del tráfico de contenedores. A ello, debemos unir los importantes efectos económicos de este sector tanto en términos de empleo y de la propia actividad portuaria (efectos directos), en la cadena de suministro (efectos indirectos) y en el conjunto de la economía (efectos inducidos), en un sector que mueve aproximadamente el 80 por 100 de las mercancías que consumimos y que tiene un peso determinante en los costes logísticos y, por tanto en el precio final de los productos (COM, 2013).

Considerando el potencial económico y el rol vital para la economía española de sus puertos, resulta necesario destacar el alto riesgo de restricción a la competencia que podemos encontrar en estas infraestructuras. La concentración de decisiones en pocos agentes, los esquemas regulatorios que pueden presentar incentivos perversos, la escasa competencia por motivos naturales como los geográficos o la limitación de espacio, o el mal diseño de los sistemas de concesiones pueden dar lugar a comportamientos poco competitivos.

En este documento hemos realizado un estudio de las principales fuentes de competencia que pueden darse lugar en estas infraestructuras. A partir del análisis tradicional donde se contemplan la competencia por el puerto, entre puertos y en el puerto en sí, hemos establecido una serie de niveles teóricos donde podemos encontrar fuerzas de competencia. Atiendo a criterios relativos a la competencia geográfica, el número de terminales por puerto, el tipo de tráfico y la relación del puerto con la población que abastece, principalmente, hemos determinado los condicionantes que pueden provocar una falta de competencia y que, por tanto, deben ser atendidos con especial interés. Aun así, este análisis multicriterio detecta aquellos casos donde existen condiciones «habitables» para las prácticas restrictivas de la competencia. Sin embargo, denotamos la existencia de comportamientos colusivos en puertos o terminales con una atmósfera inicialmente competitiva (véase los casos de Valencia o Barcelona). En estos casos, la regulación económica torna vital para garantizar una competencia efectiva. Por tanto, esta investigación se convierte en un análisis exploratorio inicial de competencia en el sistema español, que deberá ser complementado con la implementación de análisis de causalidad entre los factores mencionados y los diferentes niveles de competencia determinados en este estudio.

\section{Referencias bibliográficas}

[1] ACOSTA, M.; CORONADO, D. y CERBAN, M.M. (2007): «Port competitiveness in container traffic from an internal point of view: the experience of the Port of Algeciras Bay». Maritime Policy \& Management, 34 (5), 501-520.

[2] ANDRES, L.; J. L. GUASCH y M. DIOP (2007): «Assessing the governance of electricity regulatory agencies in the Latin American and the Caribbean Region: A Benchmarking analysis». World Bank Policy Research Working Paper No. 4380. 
[3] ASHAR y RODRIGUE (2012): The Geography of Transport Systems, Department of Geography, Hofstra University Hempstead, New York. http://people.hofstra.edu/ geotrans/eng/ch3en/conc3en/containerships.html.

[4] CABRERA, M.; A. SUÁREZ-ALEMÁN y L. TRUJILLO (2014): «Public Private Partnerships in Spanish Ports: Current status and future prospects». Utilities Policy (forthcoming).

[5] CASTILLO-MANZANO y LÓPEZ (2003): «Justificación económica de la intervención del sector público en la actividad portuaria». Cuadernos de Información Económica, $177,120-129$.

[6] CEPAL (2012): Unidad de servicios de infraestructura, División de Recursos Naturales e Infraestructura. Ed. 313 (9). Chile.

[7] COM (2014): Recomendación del Consejo relativa al Programa Nacional de Reformas de 2014 de España y por la que se emite un dictamen del consejo sobre el programa de estabilidad de 2014 de España.

[8] COM (2013): Europe's Seaports 2030: Challenges Ahead. European Commission, $\mathrm{Memo} / 13 / 448$.

[9] COM (2012a): Vice-President and Commissioner for Transport speech. Steering a course for the future: Europe's ports in the 21st century. Speech/12/352.

[10] COM (2012b): Importance of ports for economic recovery and jobs. European Commission, Memo /12/317. 12 May 2012, Brussels.

[11] COM (2011): White Paper. Roadmap to a Single European Transport Area - Towards a competitive and resource efficient transport system. European Commission, 144 final.

[12] COM (2009): Strategic goals and recommendations for the EU's maritime transport policy until 2018. Communication from the Commission to the European Parliament, the Council, the European Economic and Social Committee and the Committee of the Regions, 8 final.

[13] COMISIÓN NACIONAL DE LA COMPETENCIA (2007): Expediente 2805/07, Empresas Estibadoras a 03 de Diciembre de 2007.

[14] CHLOMOUDIS, C. I. y PALLIS, A. A. (1998): «Ports, Flexible Specialisation, and Employment Patterns». 8th World Conference on Transport Research, Antwerp, 1998.

[15] DEFILIPPI, E. (2004): «Intra-Port Competition, Regulatory Challenges and the Concession of Callao Port». Maritime Economics and Logistics, 6 (4), 279-293.

[16] DE LANGEN, P. W. y A. A. PALLIS (2006): «Analysis of the benefits intra-port comp etition». International Journal of Transport Economics, 33 (1), 69-85.

[17] DE LANGEN, P. W. DE (2002): «Clustering and Performance: The case of maritime clustering in the Netherlands», Maritime Policy and Management, 29 (3), 209-221.

[18] EPEC (2013). Market update. Review of the European PPP market in 2013. European PPP expertise centre.

[19] EBELING, C.E. (2009): «Evolution of a Box». Invention and Technology, 23 (4), 8-9.

[20] EUROSTAT (2011): Eurostat Regional Yearbook 2011. Coastal Regions, 13.

[21] FAGEDA, X. y GONZALEZ-AREGALL, M (2014): «Port charges in Spain: the roles of regulation and market forces». International Journal of Shipping and Transport Logistics, 6 (2), 152-171.

[22] FARREL, S. (2012): «The ownership and management structure of container terminal concessions». Maritime policy and management, 39 (1), 7-26.

[23] FLEMING, D. K. y BAIRD, A. J. (1999): «Some reflections on port competition in the United States and Europe». Maritime Policy and Management, 26 (4), 383-394. 
[24] GARCÍA ALONSO y MARTÍN BOFARULL (2007): «Impact of Port Investment on Efficiency and Capacity to Attract Traffic in Spain: Bilbao versus Valencia». Maritime Economics \& Logistics, 9, 254-267.

[25] GARCÍA, L. y SÁNCHEZ, R. (2006): Estadios de la Competencia Interportuaria: del marco institucional a la conducta estratégica. Universidad de Oviedo.

[26] GONZÁLEZ LAXE, F. y CORTI, I. N. (2012): Competitividad de los puertos españoles: Respuestas del sistema portuario ante la crisis económica. Universidad de Jaén.

[27] GONZÁLEZ, M. y TRUJILlO, L. (2009): «Efficiency Measurement in the Port Industry: A Survey of the Empirical Evidence». Journal of Transport Economic and Policy, 43 (2), 157-192.

[28] GOSS, R. O. (1999): «On the distribution of economic rent in Seaports». International Journal of Maritime Economics, 1 (1), 1-9.

[29] GUASCH, J. L., A. SUÁREZ-ALEMÁN y L. TRUJILLO (2013): «Structure, financing and risk management in large ports infrastructure concessions. The Chilean case». Mimeo Working Paper.

[30] GUASCH, J. L. (2004): Granting and Renegotiating Infrastructure Concessions. Doing it right. World Bank Institute, Washington, D.C.

[31] HARALAMBIDES, H. E. (2002): «Competition, excess capacity, and the pricing of port infrastructure». International Journal of Maritime Economics, 4, 323-347.

[32] HEAVER, T. (1995): «The implications of increased competition among ports for port policy and management». Maritime Policy and Management, 22, 125-133.

[33] LPI (2014): Logistics performance indicator. The World Bank. http://data.worldbank. org/indicator/LP.LPI.OVRL.XQ/

[34] MEDDA, F. y TRUJILLO, L. (2009): «A Boost for Short Sea Shipping: The Environmental and Economic Determinants». The Environmentalist, 80, 14-20.

[35] MEYER, John Robert (1959): The economics of competition in the transportation industries. No. 107. Harvard University Press.

[36] MINISTERIO DE HACIENDA (2014): «Elementos para la elaboración del Acuerdo de Asociación de España 2014-2020». Dirección General de Fondos Comunitarios. SG de Programación Territorial y Evaluación de los Programas Comunitarios. 22 de abril de 2014.

[37] MINISTERIO DE FOMENTO (2011): Observatorio de transporte intermodal. Executive summary. Gobierno de España.

[38] NG, K.Y. (2006): «Assessing the attractiveness of ports in the North European container transhipment market: an agenda for future research in port competition». Maritime Economics and Logistics, 8 (3), 234-241.

[39] NOTTEBOOM, T. E. (2002): «Consolidation and contestability in the European container handling industry». Maritime Policy and Management, 29 (3), 257-269.

[40] NOTTEBOOM, T. (1997): «Concentration and load centre development in the European container port system». Journal of Transport Geography, 5 (2), 99-115.

[41] NÚÑEZ SÁNCHEZ, R.; P. COTO MILLÁN y M.A. PESQUERA (2014): «Cambio tecnológico y eficiencia económica en la gestión de las infraestructuras portuarias españolas». Papeles de Economía Española, 131, 228-239.

[42] PAIXÃO, A. C. y MARLOW, P. B. (2002): «Strengths and weaknesses of Short Sea Shipping». Marine Policy, 26 (3), 167-178.

[43] PUERTOS DEL ESTADO (2012). Cuenta de pérdidas y ganancias. 
[44] PUERTOS DEL ESTADO (2012): Informe estadístico del Sistema de Puertos del Estado.

[45] RODRIGUE, J. P. (2013): The Geography of Transport Systems. 3. a ed. Nueva York: Routledge.

[46] ROUMBOUTSOS, A.; R. AGREN y A. SUÁREZ ALEMÁN (2013): «PPP supply market: building expertise or pure concentration». Working Paper.

[47] RÚA COSTA, C. (2006): «Los puertos en el transporte marítimo». Revista del Institut d'Organització i Control de Sistemes Industrials, 1-20.

[48] SIEMONSMA, H.; W. VAN NUS y P. UYTTENDAELE (2012): «Awarding of Port PPP contracts: the added value of a competitive dialogue procedure». Maritime Policy and Management, 39 (1), 63-78.

[49] SLACK, B. (1985): «Containerization, inter-port competition and port selection», Maritime Policy and Management, 12 (4), 293-303.

[50] SONG, D. W. (2003): «Port co-opetition in concept and practice»», Maritime Policy and Management, 30 (1), 29-44.

[51] SUÁREZ-ALEMÁN, A. y HERNÁNDEZ, A. (2014): Incentives to reduce port inefficiency: a theoretical approach. Maritime Policy and Management, 41 (5), 462-479.

[52] SUÁREZ-ALEMÁN, A.; L. TRUJILLO, y F. MEDDA (2014): «Short Sea Shipping and intermodal competition: a theoretical analysis of European maritime transport policy». Maritime Policy and Management (ahead-of-print, 1-18).

[53] SUÁREZ-ALEMÁN, A.; L. TRUJILLO y K. CULLINANE (2014): «Time at Ports in Short Sea Shipping: When Timing Is Crucial». Maritime Economics and Logistics, 16, 399-417.

[54] SWD (2014): Documento de trabajo de los servicios de la Comisión, Evaluación del Programa Nacional de Reformas de 2014 del Programa de Estabilidad de 2014 de España; que acompaña al documento COM (2014). Recomendación del Consejo relativa al Programa Nacional de Reformas de 2014 de España y por la que se emite un dictamen del consejo sobre el programa de estabilidad de 2014 de España.

[55] TCE (2012): Special Report, No 4. «Using structural and cohesion funds to co-finance transport infrastructures in seaports: an effective investment?» Pursuant to Article 287 (4), second subparagraph, TFEU.

[56] THE WORLD BANK (2013): «Logistics Performance Index». http://data.worldbank. org/indicator/LP.LPI.OVRL.XQ/.

[57] TRUJILLO, L. y GONZÁLEZ, M. (2011): «Maritime ports». En M. Finger y R. Künneke (ed.), International Handbook for the Liberalization of Infrastructure. Edward Elgar.

[58] TRUJILlO, L. y NOMBELA, G. (1999): «Privatization and Regulation of the Seaport Industry, Policy Research», Working Paper 2181, The World Bank, septiembre.

[59] VASALLO, J. M. y GALLEGO, J. (2005): «Risk-sharing in the New Public Works Concession Law in Spain», Transportation Research Record: Journal of the Transportation Research Board, 1932, 1-9.

[60] VERHOEFF, J. M. (1981): «Seaport competition: some fundamental and political aspects». Maritime Policy and Management, 8 (1), 49-60.

[61] WILMSMEIER, G., J. HOFFMANN y R. SÁNCHEZ (2006): «The Impact of Port Characteristics on International Maritime Transport Costs». Research in Transportation Economics, 16 (1), 117-140. 